\title{
A Multidimensional Framework for Understanding Tax Audit Effectiveness in Developing Countries
}

\author{
Mohammed Abdullahi Umar*, Chek Derashid and Oluwatoyin Muse Johnson Popoola
}

Tunku Puteri Intan Safinaz School of Accountancy, Universiti Utara Malaysia

\begin{abstract}
Taxation in developing countries is different from the practice in advanced countries. There is, therefore, the need to contextualize tax research in developing countries. One of the significant differences between the two regions is the practice of tax audits. In advanced countries, the probability of tax audit is seen as a deterrence to tax noncompliance. However, this study argues that this may not be the case in developing countries. The paper presents tax audits in developing countries as a three-dimensional process consisting of audit probability, detection and sanction. The paper argues that these three aspects are distinct and must all work together to ensure an effective audit. For instance, after an audit, there is a need for detection to take place. Otherwise, the entire process will be ineffective. Furthermore, after detection, there is a need for sanction before the audit process can serve as a deterrent. Detection without sanction renders the entire process ineffective. In developing countries, audits can take place without detection and detection may occur without any sanction because tax evaders can compromise the system through bribery and corruption. The paper makes a significant contribution both to the literature and practice. There is a need for researchers to focus on the three dimensions of tax audit in developing countries rather than a holistic audit probability, as found in some studies from advanced countries. Additionally, practitioners should measure tax audit effectiveness based on the three dimensions proposed in this study.
\end{abstract}

Keywords: Tax audit, developing countries, audit probability, detection, sanction

JEL Classification: $\mathrm{H} 2, \mathrm{M} 42$

Paper Type: Review

*Corresponding author: E-mail: m.abdullahi.umar@uum.edu.my 


\section{INTRODUCTION}

Tax noncompliance, though present in all societies since the beginning of taxation, is unusually high in developing countries. After about sixty years of research on taxation in developing countries, beginning from Kaldor's (1963) seminal exposition, there appears to be a consensus that noncompliance constitutes one of the biggest challenges (Bird, 2015; IMF, 2015, McKerchar \& Evans, 2009; Besley \& Persson, 2014).

Tax noncompliance is a sensitive and at times, controversial issue as it lends itself to divergent theoretical and legal interpretations. Hence, it is common to come across terms like evasion, avoidance and noncompliance used interchangeably. For Kirchler (2007), tax compliance is about taxpayers' willingness to pay their taxes. It follows from Kirchler's position that noncompliance is their unwillingness to pay. McKerchar and Evans (2009) study, however, provided a helpful breakdown of activities that constitute compliance as a) registering with the revenue authority as required, b) filling the required returns on time, c) accurately reporting tax liabilities (in the required returns) in accordance with the prevailing legislation, rulings, return instructions and court decisions, and d) paying any outstanding taxes as they fall due.

This breakdown of activities that constitute compliance by McKerchar and Evans follows the earlier position of Brown and Mazur (2003). This paper sees noncompliance as all acts contrary to the spirit and letters of compliance, as noted by McKerchar and Evans (2009). Current data on tax noncompliance across developing countries are worrisome and largely affirm the position of experts that noncompliance is the current obstacle facing taxation in developing countries. For some instances, Kangave, Nakato, Waiswa and Zzimbe (2016) investigated 60 top lawyers (commercial firms) in Uganda. They found that only 12 paid income tax in 2012 and only 13 paid in 2013, translating to about 79 per cent noncompliance. In 2014, the Nigerian Minister of Finance at that period, Ngozi Okonjo-Iweala, presented startling statistics of noncompliance with tax provisions. She stated that 75 per cent of registered firms are not in the tax system, and even among those registered, 65 per cent had not paid taxes for two years. She blamed the massive noncompliance on the self-employed (Okonjo-Iweala, 2014).

Furthermore, McCluskey (2016) asserted that only 100 high-net-worth individuals are registered with the tax revenue authority in Kenya out of an estimated 40,000. For South Africa, the figure is no less worrisome. McCluskey stated that 114,000 high-net-worth individuals fail to fulfil their tax obligations resulting in a loss of revenue of about $\$ 10.9$ billion. In the same vein, Fjeldstad and Heggstad (2011) painted a grim picture of tax compliance in Tanzania. They stated that out of a population of 45 million, only 400,000 people were registered for tax purpose in 2010 and only 400 large taxpayers contributed 80 per cent of total tax revenue while an overwhelming majority absconded from their tax obligations.

While the above data are mainly from countries of sub-Saharan Africa, developing countries from other regions are also affected by the scourge of tax noncompliance. For instance, Everest-Phillips (2010) noted that only one per cent of the population pays tax in Bangladesh, and this is in sharp contrast to more than 50 per cent in advanced countries. Sabaini and Jimenez (2012) observed that the rate of tax evasion in Guatemala is about 64 per cent, while the average for Latin America is about 50 per cent. In Europe, IMF (2013) pointed out that the more affluent population of self-employed people mostly evades the tax system.

There has been a long and winding thread of research findings on the factors influencing tax compliance behaviour since the seminal work of Allingham and Sandmo (1972). Allingham and Sandmo's work framed the taxpaying decision as a rational economic choice between the possibility of gain, if undetected by audit, and loss if 
detected and fined. The implication of Allingham and Sandmo's work is the emphasis on audit as a potent tool for tackling noncompliance.

However, Allingham and Sandmo (1972) came under persistent attack by numerous research findings that subscribe to the socio-psychological school of thought (Kirchler, 2007). For these latter schools of thought, the level of tax compliance is higher than audit alone could explain. Other socio-psychological variables are definitely at work. Elfers (2000, p.185) took the argument against audit to the extreme when he asserted that: "the gloomy picture of massive tax evasion is a phantom." The new wave of research findings after Allingham and Sandmo focused on factors like social norms (Wenzel, 2004; Bobek et al., 2007; 3013), tax morale (Torgler, 2002), tax knowledge and awareness (Erickson \& Fallan, 1996), and other numerous socio-psychological variables. As noted by Kirchler (2007), the American Inland Revenue Service (IRS) has found over sixty factors that influence tax compliance.

Despite the popularity of the socio-psychological factors in contemporary tax compliance research, this study revisits audit in an attempt to understand the massive problem of noncompliance in developing countries. The need to revisit the audit and its role in noncompliance in developing countries is justified by the extensive nature of the problem as recounted earlier.

The essential questions that guide this study are: given the extensive nature of noncompliance in developing countries is audit effective in dealing with the problem? In dealing with the problem of noncompliance in developing countries, what constitutes audit effectiveness? These questions are crucial in understanding tax noncompliance in developing countries. While advanced countries have performed comparatively well in enforcing tax compliance, developing countries continue to face daunting challenges. The audit system in advanced countries may not be perfect, but at least, it has managed to keep evasion at a relatively tolerable level. In developing countries, it appears what is going on is 'evasion with impunity' and the inability of the audit to perform its deterrent role could be a significant problem.

In the context of developing countries, Elffer's (2000) contention that the massive noncompliance predicted in the absence of audit is a phantom could be wrong. It appears the massive tax noncompliance is a reality given the statistics on noncompliance in developing countries earlier presented. Moreover, Kirchler (2007) warned that when audits are not effective such that they fail to detect and punish evaders, it may become counterproductive leading to hitherto compliant taxpayers joining the cheating folks. This appears to be a problem in developing countries.

This study investigates the concept of audit effectiveness and provides supports through qualitative interview data and an analytical review of previous studies. The study adopts the systems theory approach and argues that extant research findings on the probability of audit, detection probability and fines, as it were in advanced countries, may not be adequate in the context of developing countries. What will suffice is a systemic approach where audit effectiveness is seen as the bigger picture while probability, detection and sanction are constituent elements.

\section{OVERVIEW OF THE LITERATURE}

This section presents an overview of the literature on the effect of audit on tax compliance. However, it will be intentionally restricted to a brief overview as detailed reviews are available elsewhere (Andreoni, Erard \& Feinstein, 1998; Ritsatos, 2014). Research on the effect of audit on tax compliance has presented over time highly inconsistent results. This brief overview highlights some findings over the past 40 years. Though tax compliance 
has been an issue of concern for centuries, empirical research on the determinants of the individual's decision to comply is relatively recent.

Allingham and Sandmo (1972) kick-started scholarly interest in the phenomenon, and their findings emphasized the central position of audit in influencing compliance. The authors investigated audit in terms of audit probability (the chance of being subjected to audit) and penalty (fine accruing from the detection of evasion). Other researchers after Allingham and Sandmo have followed this philosophy of audit with slight variations in some cases. There are also differences in the types of data and methods employed by various studies.

However, previous studies were mostly conducted in advanced countries, and in these studies, the dividing lines between the probability of audit, detection and penalty appears blurry. There is a need for caution in following these dimensions, as some authors used them interchangeably or together. For instance, Slemrod, Blumenthal and Christian (2001, p.45) in their work on audit probability, discussed detection and penalty ".... what might deter an individual from income tax evasion is a fixed probability that any taxable income understatement will be detected and subjected to penalty...". The assumption of Slemrod et al. is that detection leads to penalty; hence, taxpayers are deterred by a probability of detection. Other studies hold similar assumptions. For instance, Alm and McKee (2006) investigated audit certainty and audit productivity. The authors defined audit certainty in line with audit probability-taxpayers are informed that they will be audited-while productivity implies the level or capacity of the audit to detect evasion.

Unlike Slemrod et al. (2001), Alm and Mckee (2006) were silent on the penalty. This is not surprising; perhaps, it is taken for granted that the detection of evasion will automatically lead to sanction. Results from Slemrod et al. (2001) were not consistent as some groups were indifferent to the threat while it only marginally affected other groups. Interestingly, Slemrod et al. concluded that the undeterred groups would have concluded that the resource-constrained tax agency could not execute such an extensive audit that could pose a threat to them or that even if they did, they could not detect their evasion schemes. This is in line with the thesis of this study that audit events may not lead to detection and detection may not lead to sanction.

In his study, Dubin (2007), who investigated the impact of activities of the Criminal Investigation Division (CID) of the IRS, found a strong influence of CID activities and penalty on tax compliance. The author stated that doubling the audit rate increase collections significantly. He referred to these collections as "reported amounts and additional taxes and penalties" (p.500). The study also contended that incarceration and probation rather than fines have a more significant influence on compliance. While Dubin (2007) provided additional insight into the subject of an audit, it follows the pattern of previous studies from advanced countries (Slemrod et al., 2001; Alm \& Mckee, 2006).

From the author's statement, 'doubling' audit rate leads to higher tax collections. There is an implied assumption that the 'doubled' audit rate could automatically lead to detections and sanctions; hence, taxpayers take caution by being more compliant. However, as this study will argue later, the circumstances in developing countries are quite different, and the assumptions of researchers in advanced countries may not fully hold in developing contexts. Audit probability may not always lead to detection, as many factors determine detection. Moreover, detection may not always lead to sanction. Though the assumption could work in advanced countries, Fisher et al. (1992) cautioned that it may not always work that way.

Previous studies on audit present substantial divergence in their findings. One of the factors that may have contributed to the inconsistencies in audit research is the varieties of data and methodologies (Fisher et al., 1992). For instance, the studies of Alm et al. (1992, 1995) and Alm and McKee (2006) were based on experimental methods which 
utilized proxy samples (students). While such studies have consistently found a positive effect of audit probability and fine on compliance, the experimental study of Slemrod et al. (2001) found different results.

The population of Slemrod et al. studies were real taxpayers served with real letters from the Minnesota revenue authority. From this contrast in the experimental sample, it is not surprising that these studies came up with divergent findings. Dubin's (2007) study and some others utilized taxpayer data provided by the IRS. This is a secondary data, and it is fraught with enormous challenges for researchers trying to decipher meaning and patterns from it (Alm, 2012). In concluding this section, it is important to reiterate the inconsistencies of research findings on audit as it relates to tax compliance.

Additionally, most of the studies were conducted in the advanced countries, leaving the developing countries in need of an audit framework to tackle the massive tax noncompliance in that part of the world. In doing so, there is a need for researchers to define audit more coherently to avoid the inconsistency trap that previous research fell. This study attempts to fill this gap especially as it affects developing countries. Moreover, this study supports its investigation with qualitative evidence from interviews with taxpayers, thus gaining insights from the major actors in the tax compliance game-the taxpayers (Bird, 2015).

\section{FRAMING OF AUDIT EFFECTIVENESS IN THE CONTEXT OF DEVELOPING COUNTRIES}

Based on the overview of the literature in section two and qualitative evidence in section three, this section presents a framework for a more coherent understanding of the audit, especially as it applies to developing countries. One might be curious about whether it makes sense to provide a different framework for understanding tax compliance in developing countries from what is obtainable in advanced countries. As noted by Burgess and Stern (1993), in the field of taxation, developing countries face peculiar challenges such that any attempt to understand taxation in the same as the manner it is understood in advanced countries would 'go badly wrong'. In providing an audit framework for developing countries, this study is guided by the peculiarities of their contexts such that some assumptions that work in the more advanced countries could fail woefully in developing countries.

One common assumption that runs through the conceptualization of audit in studies from the advanced countries is that the probability of audit leads to detection (Fisher et al., 1992). This can be noticed even in the seminal work of Allingham and Sandmo (1972), where it was concluded that audit probability and fines deter potential tax-evaders. There is also the assumption that detection leads to a penalty. Nearly all the economic approaches to the study of tax compliance behaviour have followed the assumptions of Allingham and Sandmo (1972) thus perpetuating this line of thought. This line of thought holds that the probability of audit has a deterrent effect on taxpayers (Slemrod et al., 2001; Dubin, 2007).

Alm and McKee (2006) however investigated detection probability alongside audit probability. A study like Alm et al. (1992) investigated separate effects of audit probability and sanction but was silent on detection. In all these studies, and based on findings from the qualitative data earlier presented, it can be seen that three distinct activities are involved in the entire audit system-audit probability (chance or rate of audit), detection probability, and sanction (fine or prosecution).

Some studies chose to investigate audit probability as a stand-alone construct (Alm et al., 1992; Dubin, 2007), while others investigated detection probability (Alm \& McKee, 2006). Others investigated the influence of sanctions as a stand-alone concept (Alm et al., 
1992). While all the above studies were conducted in advanced countries and could be adequate for their context, developing countries need a system theory approach to tackling the challenges of the audit.

The audit process operates in stages and operates within a system from the chance that a taxpayer would be audited (which depends on the audit rate), to the possibility of detection (which depends on the skills of auditors and other factors) and finally to prosecution or fine if evasion is detected (this depends on the level of the rule of law and judiciary). This is neither a one-off nor a simple system. Instead, it could be a long and complicated process, especially in developing countries. For instance, the probability of audit determines whether a taxpayer will be audited or otherwise. However, unlike the advanced countries, audit rate or probability does not translate to automatic detection in developing countries because detection is determined by other variables such as experience and integrity of the auditors (Wang, 2001). To worsen matters, even if detection is made, fine or prosecution is not automatically guaranteed in developing countries because it could be frustrated by other agencies involved in the system.

The entire audit system is constituted by a flow of activities, as depicted in Figure 1 from audit probability to sanction (prosecution or fine). Secondly, the audit process is organized in a complementary system where one part supports the other to attain a holistic objective of deterrence. This is depicted in figure 2 .

\section{Stage 1}

Stage 2

Stage 3

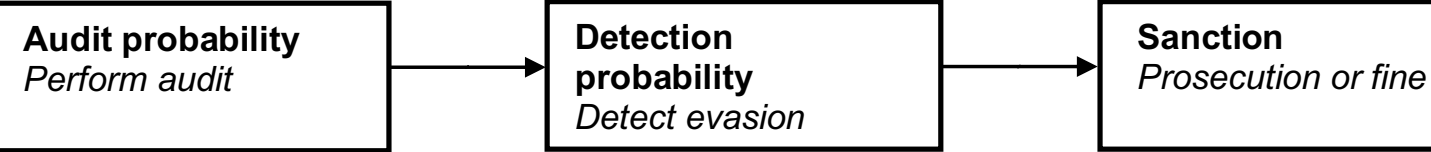

Figure 1. Process flow of tax compliance audit

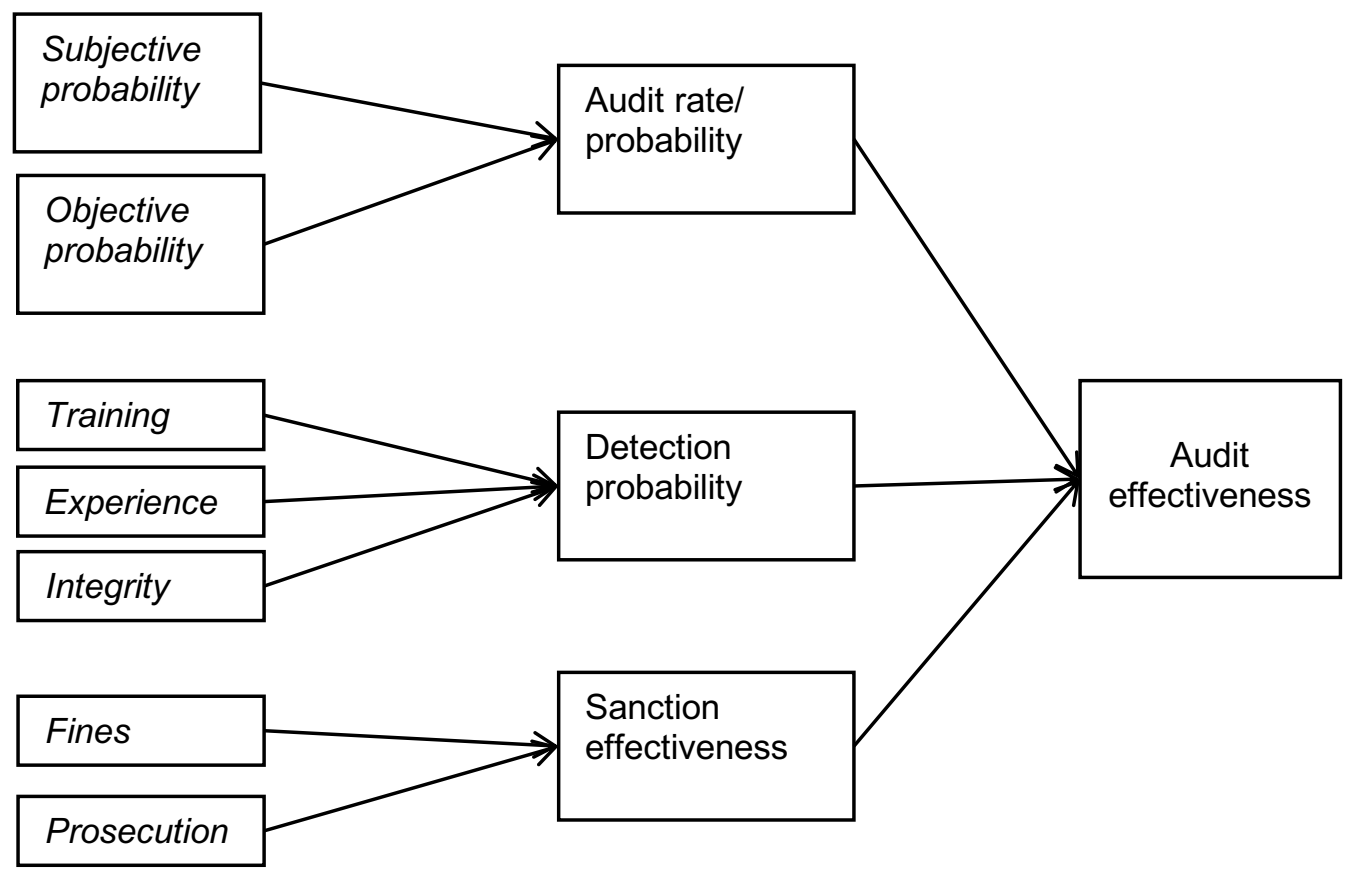

Figure 2. Audit effectiveness and its composite elements 
The process flow in figure one shows the stages the tax compliance audit undergoes before attaining the deterrence objective. The first encounter of the taxpayer with the audit system is the probability of audit. As noted by Allingham and Sandmo (1972), this stage is laden with uncertainty. Will the taxpayer be audited or not? What is the rate of audit, and what are the chances that the taxpayer will be picked for an audit? This is a critical point in the audit process.

Previous studies in the advanced countries found that a high probability of audit influence the decision to comply at this stage. In advanced countries, this is understandable because stage one in the audit process flow can easily lead to stage two. In other words, should audit take place (stage one), detection is most likely (stage two)? As stated earlier, this progression from stage one to stage two is fraught with difficulty in developing countries.

Anyone or a combination of two of the following things could happen to thwart the progression from an audit event to detection. Firstly, the auditor may not have the requisite training, experience and equipment to detect evasion hence will remain stuck at stage one without progressing to stage two (detection). Secondly, the auditor may have the capacity to detect, but given that he operates in a rent-seeking system, he prefers to strike a bribery deal with the evader. Similar to the first scenario, the audit process also gets stuck at stage one, failing to progress to stage two. The implication of this analysis is that, unlike advanced countries where researchers investigated the probability of audit and found it to influence compliance profoundly, developing countries are different. The probability of an audit does not always lead to detection.

Furthermore, the second progression in the audit process flow is from detection to sanction (fine or prosecution). Studies in the context of advanced countries have reported the positive effect of detection probability on tax compliance. The assumption in these studies is that detection will lead to sanction, prosecution or fine. Again, this is most likely in advanced countries, but in the context of developing countries, detection (stage two) in the process flow in Figure 2 may not lead to sanction (prosecution or fine) which is stage three. Similar to the progression from stage one to two, the auditor may trade off sanction for personal gain.

Additionally, even if the auditor reports the case for possible sanction, that is just the beginning of a lengthy and complicated process which may not result in prosecution or fine. It should be noted that the auditor who uncovers evasion is not himself responsible for prosecution. The judiciary has to prosecute evaders reported by the auditors. In developing countries, the judicial process is notorious for frustrating efforts aimed at enforcing tax compliance (Everest-Phillips, 2010; Bes, 2007). This much was reiterated by participants in the interviews earlier presented.

Bes (2007), who reviewed tax administration reforms in Argentina, concluded that improvements failed to translate to higher tax revenues due to a corrupt judiciary. This supports the position that audits are only effective when cases of malpractice are eventually sanctioned (prosecution or fine). The preliminary stages of audit probability or detection probability cannot determine the effectiveness of the system. Further support for this contention is offered by Everest-Phillips (2010). He narrated the case of Yemen where recalcitrant tax-evaders prefer that their cases be taken to court. This enables them to avoid paying the amount due while litigations lasted, but this could take between seven to nine years! The court cases, most likely, would never conclude, and even if they were concluded, it would be at a cost many times higher than the contested amount of tax.

Apart from being a process flow from audit probability to detection and sanction, the three elements of the audit system are complementary such that it is challenging for anyone or two stands on their own. For instance, if audit probability is sufficient such that audits are very likely, and detection is also effective, failed sanction will render them 
useless. If detections are effective and sanctions are swift and efficient, evaders would not suffer detection and sanction until they are audited in the first instance (audit probability). Should they face zero probability of audit, then detection and sanction become a nonissue. Similarly, when audit probability and sanctions are effective, a gap in detection renders the first two impotent.

As shown in Figures 1 and 2, audit effectiveness is a construct that can only be valid when its three components (audit probability, detection probability, and sanction) work together. Anything less reduces the potency of audit effectiveness. As emphasized earlier, this argument, though appropriate for research in advanced countries, is most applicable to developing countries where the systems are ineffective and vulnerable to leakages from all areas. Johnson, Kast and Rosenzweig (1963, p.367) defines a system as 'an organized or complex whole; an assemblage or combination of things or parts forming a complex or unitary whole.' System theory supports the findings of this study. While audit effectiveness is a holistic construct, it is a combination of different parts working together in a system to ensure deterrence.

\section{CONCLUSION}

The study revisits the continued massive tax noncompliance in developing countries despite over thirty years of concerted efforts by global stakeholders. While sociopsychological determinants of tax compliance remain popular in the aftermath of Allingham and Sandmo (1972), this study dwells on audit, contending that it still holds a dominant position in tackling the pervasive evasion in developing countries.

However, this study took a different analytical path in dissecting audit in developing countries. Rather than the usual assumption in dominant tax compliance research in advanced countries (Alm et al., 1992; Slemrod et al., 2001; Alm \& Mckee, 2006; Dubin, 2007), where audit probability (standing on its own), detection probability (on its own) and sanction on its own, were found to influence tax compliance, this study frames audit in terms of a composite construct of 'audit effectiveness.'

Following the positions of notable experts on this issue (Kirchler, 2007; Fisher et al., 1992), this study argues that the assumptions in previous studies that a taxpayer is deterred by audit probability or detection probability may only work in advanced countries. In the context of developing countries, the taxpayers are aware of the intricacies of the process flow from audit probability to detection and sanction. They are also aware that the process and entire system is fraught with loopholes that they could exploit to their advantage.

Given the above fact, lessons from the system theory come handy in understanding and tackling tax noncompliance in developing countries. The audit should not be seen as segregated activities such as audit probability, detection probability or sanction. Instead, it should be approached as a systemic whole of audit effectiveness. Effectiveness is attained only at the point where tax evaders are punished. Any focus on audit probability or detection that ignores the possibility of escaping sanction does not align with the system theory.

In the context of developing countries, audit probability or detection probability are mere paper tigers or toothless bulldogs that only bark. The real test for the bulldog is when it can bite. In the realm of the tax compliance audit, the bite can only occur when an evader pays fine or is behind the prison wall. Instances of these are rare in developing countries; hence, the evaders are happy to go to court.

This study comes with some limitations. The qualitative evidence was obtained from one country among so many others that constitute the developing world. This calls for caution in generalizing the findings to all developing countries as they are diverse and far 
apart. Some developing countries perform better than others. Some groups of developing countries are in transition between the developing and the advanced stages. However many experts in taxation as it applies to these countries have attested to the similarity of their tax compliance challenges (Kaldor, 1963; Burgess \& Stern, 1993, Besley \& Persson, 2014, Bird, 2015).

Moreover, the analytical insights utilized to complement the qualitative findings to apply generally. Finally, tax noncompliance remains an endemic problem in developing countries. If not checked, it portends grave danger to those countries as the fates of many of them are hanging on the balance between fragility and state failure (OECD, 2014b). As noted by Stinespring (2011) 'tax evasion deprives the government of its lifeblood and at an extreme, can hasten the state's demise'.

The prediction of Stinespring could already be catching up with developing countries. When state failure occurs due to the inadequacy of tax revenue, the repercussions are not limited to developing countries alone; they spill over to advanced countries in the form of refugee crises and demand for financial aids. Hence global stakeholders must continue in the concerted effort to tackle tax noncompliance in developing countries. In doing so, audit effectiveness holds the key to unlocking more tax revenues.

\section{REFERENCES}

Allingham, M. G., \& Sandmo, A. (1972). Income tax evasion, a theoretical analysis. Journal of Public Economics, 1(1972), 323-338.

Alm, J. (2012). Measuring, explaining, and controlling tax evasion: Lessons from theory, experiments and field studies. Tulane Economics Working Papers Series, 1213.

Alm, J., \& Mckee, M. (2006). Audit certainty, audit productivity and tax compliance. National Tax Journal, LIX(4) 801-816.

Alm, J., Jackson, B., \& Mckee, M. (1992). Estimating the determinants of taxpayer compliance with experimental data. National Tax Journal, 45(1), 107-114.

Alm, J., Sanchez, I., \& Dejuan, A. (1995). Economic and noneconomic factors in tax compliance. Kyklos, 48(1), 3-18.

Andreoni. J., Erard, B. \& Feinstein, J. (1998). Tax compliance. Journal of Economic Literature, 32(2), 816-880

Attride-Stirling, J. (2001). Thematic networks: An analytic tool for qualitative research. Qualitative Research, 1(3), 383-405.

Bes, M. (2007). Argentina in Bernandi, L, barrier, A., Marenzi, A., \& Profeta, P. (2007) Eds. Tax systems and Tax reforms in Latin America, Societa, Italiana di Economica publica, Working Paper No 587

Besley, T., \& Persson, T. (2014). Why do developing countries tax so little? Journal of Economic Perspectives, 28(4) 99-120. https://doi.org/10.1257/jep.28.4.99

Bird, R.M. (2015). Improving tax administration in developing countries, Journal of Tax Administration, 1(1), 23-45.

Bobek, D. D., Hageman, A. M., \& Kelliher, C. F. (2013). Analyzing the role of social norms in tax compliance behaviour. Journal of Business Ethics, 115, 451-468.

Bobek, D. D., Robert, R. W., \& Sweeney, J. T. (2007). The social norms of tax compliance: Evidence from Australia, Singapore and the USA. Journal of Business Ethics, 74, 49-64. https://doi.org/10.1007/s10551-006-9219-X

Brown, R. E., \& Manzur, M. J. (2003). IRS comprehensive approach to compliance measurement. National Tax Journal, 689-700. Retrieved from https://www.irs.gov/pub/irs-soi/mazur.pdf

Burgess, R., \& Stern, N. (1993). Taxation and development. Journal of Economic Literature, 31(2), $762-830$

Charmaz, K. (2006). Constructing grounded theory: A practical guide through qualitative analysis. London: Sage publications. 
Cobham, A. (2014). Nigeria's upward revision of GDP should sound alarm on the tax-to-GDP ratio. Retrieved from https://www.cgdev.org/blog/nigerias-upward-revision-gdp-should-soundalarm-tax-gdp-ratio

Creswell, J. (2013). Qualitative Inquiry and research design: choosing among five approaches. Los Angeles: Sage publications

Dubin, J. A. (2007). Criminal investigation enforcement activities and taxpayer noncompliance. Public Finance Review, 35(4),500-529.

Elffers, H. (2000). But taxpayers do cooperate! in M. Van Vught, M, Snyder, T.R. Tyler, and Andres biel (eds), Cooperation in Modern society: Promoting the Welfare of Communities, States and Organizations, London: Routledge

Eriksen, K., \& Fallan, L. (1996). Tax Knowledge and attitude towards taxation: A report on a quasiexperiment, Journal of Economic Psychology, 17(3), 387-408.

Everest-Phillips, M. (2010). State-building taxation for developing countries: Principles for reform. Development Policy Review, 28(1),75-96.

Fischer C. M, Wartick M., \& Mark, M. (1992). Detection probability and taxpayer compliance: A review of the Literature. Journal of Accounting Literature, 11, I-46

Fjeldstad, O-H., \& Heggstad, K. K. (2011). The tax systems in Mozambique, Tanzania and Zambia: Capacity and constraints. CMI Reports R 2011:3.

IMF (2013). Greece selected issues. IMF Country Report NO. 13/155

IMF (2015). Current challenges in revenue mobilization: Improving tax compliance. Washington: International Monetary Fund.

Johnson, R. A., Kast, F. E., \& Rosenzweig, J. E. (1964). Systems theory and management. Management Science, 10(2), 367-384

Joshi, A., Prichard, W., \& Heady, C. (2014). Taxing the informal economy: The current state of knowledge and agendas for future research, The Journal of Development Studies, 50(10), $1325-1347$.

Kaldor, N. (1963). Will underdeveloped countries learn to tax? Council on foreign relations: Foreign Affairs, JAN, 1963.

Kangave, J., Nakato, S., Waiswa, R., \& Zzimbe, P. L. (2016). Boosting Revenue collection through taxing high net worth individuals: The case of Uganda. ICTD working Paper NO. 2541.

Kirchler, E. (2007). The economic psychology of taxpayers behaviour. Cambridge: Cambridge University Press.

McCluskey, R. (2016). Why African governments should tax the rich. International Center for Tax and Development, International Center for Tax and Development.

McKerchar, M. \& Evans, C. (2009). Sustaining growth in developing economies through improved taxpayer compliance: Challenges for policy makers and revenue authorities. Ejournal of Tax Research, 7(2), 171-201

OECD (2014). OECD Development co-operation peer reviews, OECD Publishing. https://doi.org/10.1787/23097132

OECD (2014b). Fragile States, 2014. Domestic revenue mobilization in fragile states. Retrieved from https://www.gfintegrity.org/wp-content/uploads/2014/05/OECD-Fragile-States-Report2014.pdf

Okonjo-Iweala, N. (2014). In my view: Development depends on realizing the potential of taxation. OECD Insights. Retrieved from http://oecdinsights.org/2014/10/09/in-my-view-developmentdepends-on-realising-the-potential-of-taxation/

Ritsatos, T. (2014). Tax evasion and compliance, from the neoclassical paradigm to behavioural economics, a review. Journal of Accounting and Organizational Change, 10(2), 244-262. https://doi.org/10.1108/JAOC-07-2012-0059

Sabaini, J. C. G., \& Jimenez, J. P. (2012). Tax structure and tax evasion. CEPAL macroeconomic del desarrolo No. 118

Slemrod, J., Blumenthal, M., \& Christian, C. (2001). Taxpayer response to an increased probability of audit: Evidence from a controlled experiment in Minnesota. Journal of Public Economics, 79, 455-483.

Stinespring, J.R. (2011). Dynamic scoring, tax evasion and the shadow economy. Public Finance Review, 39(1), 50-74. 
Torgler, B. (2002). Speaking to theorist and searching for facts: Tax morale and compliance in experiments, Journal of Economic Surveys, 16(5), 657-683.

UNECA (2015). Country Profile: Nigeria Retrieved from http://www.uneca.org/sites/default/files/uploadeddocuments/CoM/com2015/cp_nigeria_country_profile.pdf

Wang, S., (2001). The construction of state extractive capacity. Modern China, 27(2), 229-261.

Wenzel, M. (2004). An analysis of norm processes in tax compliance. Journal of Economic Psychology, 25, 213-228. 